\title{
Title: Ultrasound evaluation of paresthesia and nerve stimulation
}

\author{
Authors: Ahtsham Niazi MB, FCARCSI, Anahi Perlas MD, FRCPC, Vincent WS Chan MD, \\ FRCPC, Colin Mc Cartney MB, FRCA, Daquan Xu, MD \\ Department of Anesthesia and Pain Management, Toronto Western Hospital, University Health \\ Network, Toronto, Ontario, Canada
}

Introduction: Paresthesia and motor response to electrical nerve stimulation are methods of nerve localization but they do not always correlate reliably. ${ }^{1,2}$ The objective of this study is to determine the sensitivity of paresthesia and electrical stimulation by ultrasound imaging.

Methods: Seventy-five patients undergoing elective hand surgery under axillary brachial plexus block were prospectively studied. All blocks were performed under ultrasound (Philips-ATL HDI 5000 unit) and nerve stimulator (Stimuplex, Braun Medical, Bethlehem, PA) guidance. Under aseptic conditions, the median, radial, ulnar and musculocutaneous nerves were identified by ultrasonography using a linear $12 \mathrm{MHz}$ probe. A 2', 22 G insulated needle (Stimuplex, Braun Medical, Bethlehem, PA) was then inserted and advanced under real-time ultrasound guidance to contact one of the nerves. At this point the patient was asked to report a feeling of paresthesia, defined as pins and needles, electric or tingling sensation in the upper extremity, if it occured. Thereafter, the nerve stimulator ( $2 \mathrm{~Hz}$ and $100 \mathrm{msec}$ ) was switched on, and the current was gradually increased until a motor response was obtained or to a maximum of 5.0mA. Lidocaine $1.5 \%$ with 1:200,000 epinephrine $(15 \mathrm{~mL})$ was injected over the first nerve identified. The remaining three nerves were blocked in a similar fashion with a total of $40-50 \mathrm{~mL}$ of local anesthetic. Pinprick sensation, motor block and block completeness were assessed in each nerve territory every $5 \mathrm{~min}$ for $30 \mathrm{~min}$.

Results: The data presented refer to the first nerve blocked to ensure no local anesthetic had been injected prior to seeking paresthesia and motor response. Of 75 patients studied, only 28 patients $(37 \%)$ reported paresthesia. Fifty-six cases $(75 \%)$ had a motor response elicited at $<0.5 \mathrm{~mA}$ and the remaining $19(25 \%)$ had a response between 0.5 and $1.0 \mathrm{~mA}$. This first nerve was completely anesthetized in 73 patients $(97.3 \%)$ by $30 \mathrm{~min}$.

Conclusion: Our preliminary data suggest that both paresthesia and nerve stimulation $\leq 0.5 \mathrm{~mA}$ are methods of low sensitivity (37\% and 75\% respectively) for detecting needle-nerve contact when an insulated needle is used for axillary blockade.

\section{References:}

1. Choyce A, Chan V, Middleton $\mathrm{W}$, et al. What is the relationship between paresthesia and nerve stimulation for axillary brachial plexus block? Reg Anesth Pain Med 2001; 26:100-104

2. Urmey W, Stanton J. Inability to consistently elicit a motor response following sensory paresthesia during interscalene block administration. Anesthesiology 2002; 96: 552-554 